\title{
Projeto e desenvolvimento de um sistema de controle de arrefecimento de um motor Diesel, a fim de reduzir o consumo de combustível e as emissões.
}

\author{
Marco Antonio Iskandar \\ MWM International Motores Ltda. \\ E-mail: marco.iskandar@ navistar.com.br
}

\section{RESUMO}

Este projeto baseia-se no controle eletrônico de um sistema de arrefecimento do motor Diesel. A proposta do sistema descrito substitui o sistema tradicional de "arrefecimento" para um sistema mecatrónico constituído por uma bomba de água com acionamento elétrico, ventilador acionado eletricamente, uma válvula termostática controlada eletronicamente e um algoritmo de controle. Este conjunto será capaz de fazer um controle preciso da temperatura do sistema de arrefecimento, diminuindo assim a emissão de poluentes e do consumo de combustível, e que permite uma resposta rápida no aquecimento do motor na partida a frio. Depois da validação, espera-se uma proposta de projeto para estar disponível no mercado de produtos que atendam os padrões de emissões futuras, economia no consumo de combustível, durabilidade e competitividade nos mercados internacionais, tendo em conta a melhoria da relação custo-benefício.

\section{INTRODUÇÃO}

O motor de combustão interna do ciclo Diesel é uma máquina térmica que transforma a energia proveniente de uma reação química em energia mecânica, necessitando de uma fonte de energia para seu funcionamento: o combustível. Os motores Diesel podem ser divididos em dois tipos: o de dois tempos ou de quatro tempos. Os motores de quatro tempos necessitam de quatro tempos para cada ciclo completo de combustão. No primeiro ciclo, ciclo de admissão, o pistão se movimenta do ponto morto superior (PMS) ao ponto morto inferior (PMI), conforme esquema de um motor de combustão interna com arranjo cilindro e pistão apresentado na Figura 1. Durante quase todo o ciclo de admissão, o ar filtrado é induzido para dentro do cilindro. No segundo ciclo, o ar que foi induzido para dentro do cilindro é comprimido durante o deslocamento do pistão do PMI para o PMS. Este segundo ciclo é conhecido como ciclo de compressão, onde o ar existente dentro do cilindro é comprimido e aquecido a uma temperatura normalmente acima da temperatura de autoignição do combustível injetado no cilindro próximo ao PMS. Com a queima do combustível, a energia em forma de calor é liberada aumentando a pressão dentro do cilindro. Esta liberação de energia aumenta a pressão no cilindro que é aplicada à superfície do pistão fazendo com que ele retorne ao PMI. Este ciclo é conhecido como ciclo de expansão, ciclo de potência ou ainda ciclo de trabalho, pois é neste ciclo que a expansão dos gases produz trabalho aplicando pressão à superfície do pistão [1]. 

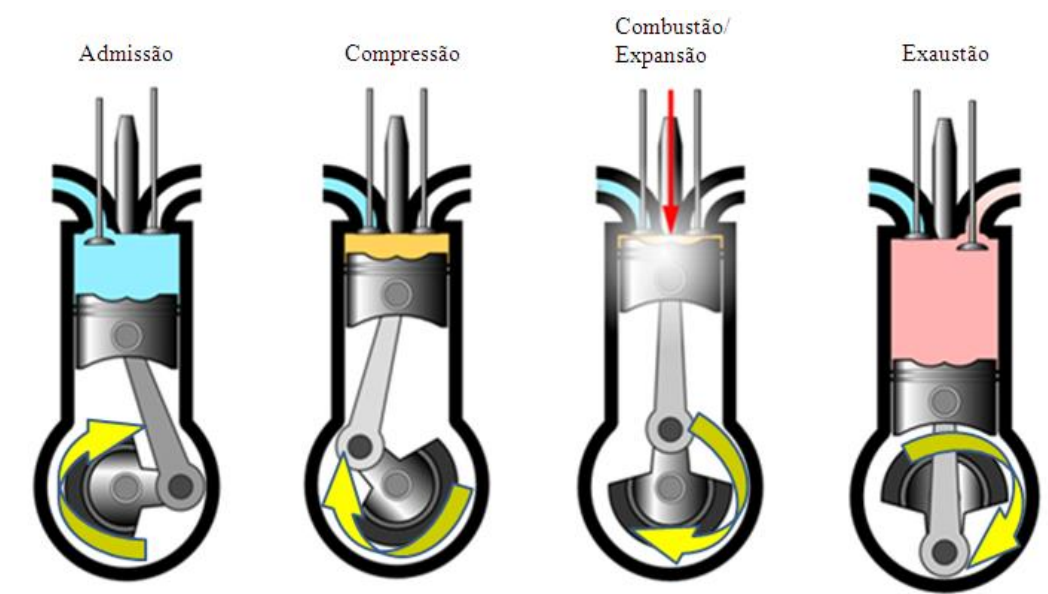

Figura 1 - Ciclo de um motor diesel de quatro tempos

Se não se considerasse a termodinâmica e a combustão no motor Diesel, sua refrigeração não seria necessária. Se pudéssemos imaginar o motor de quatro tempos sem nenhuma troca térmica entre o combustível queimando e as paredes dos cilindros, a temperatura média calculada não deveria exceder em muito a $300^{\circ} \mathrm{C}$. Os numerosos imperativos mecânicos (dilatação, fricções, resistência ao calor dos óleos etc.) e as trocas térmicas inevitáveis na prática, entre a câmara de combustão e as paredes destas, conduziram, todavia, a se conceber um sistema de refrigeração eficaz. Nos motores Diesel a combustão do combustível ocorre pelas elevadas temperaturas $\left(500{ }^{\circ} \mathrm{C}\right.$ a $\left.650{ }^{\circ} \mathrm{C}\right)$ do ar que está comprimido e aquecido e pela pressão na câmara de combustão de 65 a $130 \mathrm{kgf} / \mathrm{cm}^{2}$. Dos balanços térmicos estabelecidos pelo estudo da refrigeração dos motores, mais ou menos a terça parte da energia fornecida pela combustão é recolhida pelo eixo do motor, 35 a $40 \%$ dessa energia é dissipada pelos gases de escapamento, o resto, um pouco mais de um quarto, é perdido sob forma de calor na refrigeração. Ainda é preciso considerar que para assegurar a refrigeração, será necessário preestabelecer certa força para movimentar os sistemas auxiliares como o ventilador, a bomba de água etc., e assegurar a dissipação no ar deste calor transmitido pelas paredes do bloco e cabeçote. O óleo lubrificante representa, igualmente, um papel na refrigeração, pois ele conduz uma parte do calor que ele armazenou em contato com as paredes quentes e superfícies de atrito e que perde durante sua passagem no cárter ou eventualmente no radiador de óleo. A Figura 2 mostra que uma parte do calor produzido pela energia armazenada no combustível é transformada em energia mecânica, parte é irradiada para o ambiente, uma parte é perdida por atrito mecânico, uma parte é eliminada pelos gases de escape e uma parte do calor gerado é transferido para o sistema de arrefecimento. O elevado grau de eficiência do motor Diesel é estreitamente relacionado com os poluentes criados durante o processo de combustão, no qual o combustível é introduzido na câmara de combustão durante um curto período de tempo. A combustão rápida perto do PMS (ponto morto superior), e em combinação com o elevado coeficiente de ar de admissão conduz a uma maior eficiência do motor a diesel. A combustão rápida do combustível também está associada com elevada temperatura de combustão, o que por sua vez causam a formação de óxidos nitrogênio (NO e $\mathrm{NO} 2$, geralmente referidos como NOX). A formação do óxido nítrico (NO), se dá ao longo da faixa de alta-temperatura de gases queimados atrás da chama, através de reações químicas que envolvem nitrogênio, átomos de oxigênio e moléculas que não atingiram equilíbrio químico. 


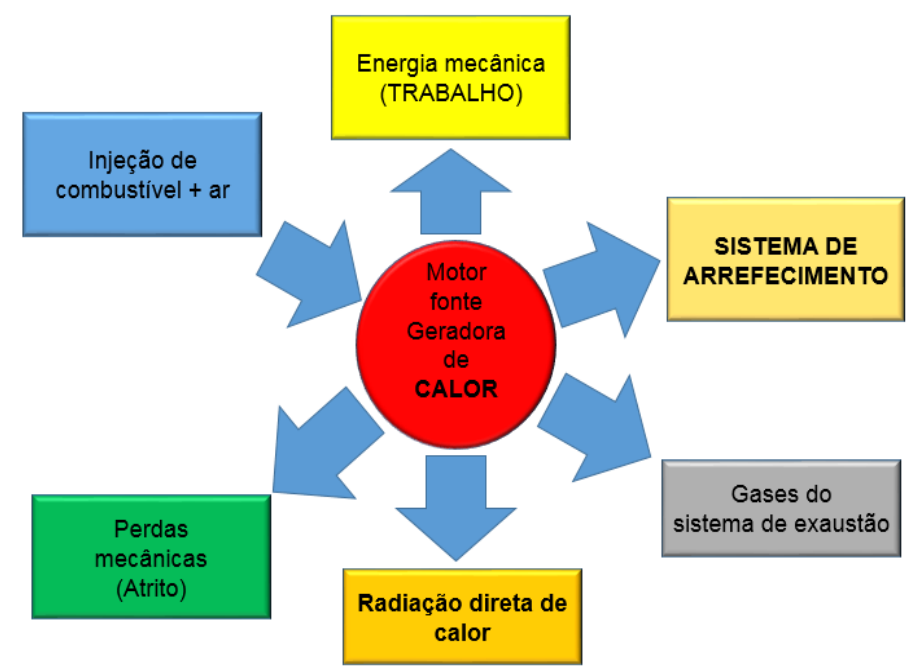

Figura 2 - Processo de geração de energia na forma de calor durante a combustão

$>$ O trabalho mecânico

$>$ Sistema de exaustão dos gases de escape

$>$ Calor removido pelo sistema de arrefecimento

$>$ Calor gerado pela fricção das peças mecânicas

$>$ Calor gerado através da radiação direta

Estes cinco itens, o que realmente importa é o trabalho mecânico. Os outros quatro pode ser considerado como energia desperdiçada. Pior, são os gases de escape, além de transportar o calor são uma fonte de poluição, que alguns dos seus componentes prejudicam intensamente o meio ambiente, os mais relevantes são: CO (monóxido de carbono), HC (combustível não queimado), NOx (óxidos de nitrogênio), SO2 (dióxido de enxofre) e MP (material Particulado). No bloco de cilindros do motor, com a liberação de energia durante a combustão, conforme apresentado na Figura 3, o calor gerado na câmara durante a combustão no interior do motor é classificado em: convecção, condução e irradiação de calor.

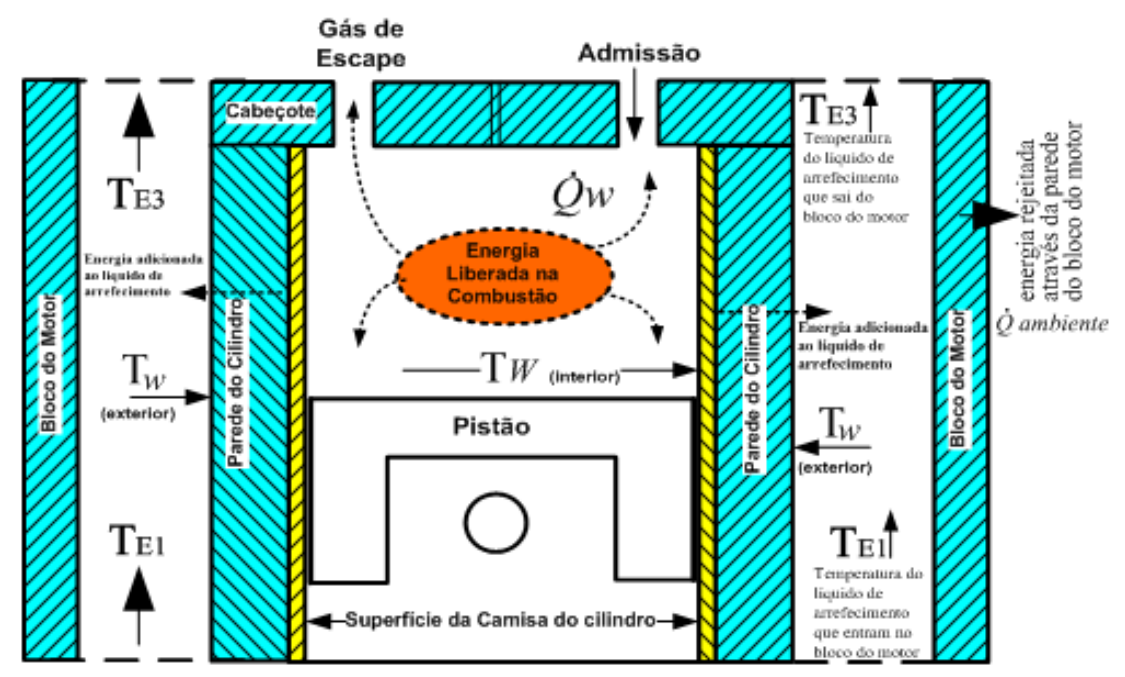

Figura 3 - Bloco de cilindros do motor com a liberação de energia durante a combustão e o circuito do líquido de arrefecimento.

$\mathrm{O}$ rendimento de um motor do ciclo diesel pode atingir de $35 \%$ a $40 \%$. A energia total desenvolvida pela combustão distribui-se do seguinte modo: 
$25 \%$ sob forma de calor gasto pelo sistema de arrefecimento dos cilindros;

$>30 \%$ sob forma de calor retirado pelos gases de escape;

$>5 \%$ sob forma de energia mecânica absorvida pelos atritos internos do motor;

$>40 \%$ sob forma de energia mecânica disponível na extremidade do virabrequim.

A variação da temperatura da entrada e saída d'água de refrigeração de um motor deve ser a menor possível, pois essa troca de calor, embora necessária, provoca perdas de energia. Portanto, essa variação de temperatura deve ser trabalhada com muito cuidado, caso contrário, o motor poderá apresentar superaquecimento ou ter uma boa parte dessa energia perdida pelo trocador de calor.

\section{REVISÃO BIBLIOGRÁFICA}

Os resultados das pesquisas sobre controle dos sistemas de arrefecimento do motor que foram publicados ao longo dos últimos anos têm como foco principal a redução do consumo de combustível e das emissões de gases poluentes e como ferramenta tem sido utilizada modelos de simulação do sistema de controle de temperatura do motor. Desde que os microprocessadores se tornaram disponíveis, confiáveis e com baixo custo, várias pesquisas têm sido feitas para aperfeiçoar e otimizar o desempenho do motor de combustão interna. A principal ênfase dada tem envolvido geralmente o controle de combustível e das emissões de poluentes, entre outras variáveis relevantes para o processo de combustão, negligenciando o sistema de arrefecimento do motor. A maioria dos motores hoje opera com uma bomba acionada mecanicamente e uma válvula termostática acionada por meio de um bulbo à base de cera. Embora eficaz para controlar a temperatura do motor, esse sistema não contribui para a economia de combustível e a redução dos níveis de emissões de poluentes.

O sistema de arrefecimento de um motor Diesel tem sido convencionalmente considerado como um sistema auxiliar, com menor importância para o desempenho do motor, embora necessário ao seu funcionamento. Os sistemas convencionais de refrigeração do motor são projetados para manter a temperatura do motor aceitável para uma ampla faixa de operação e condições de funcionamento. $\mathrm{Na}$ busca de maior economia de combustível e redução das emissões de gases poluentes, um sistema de arrefecimento do motor diesel eletronicamente controlado, deve proporcionar melhorias no seu desempenho por meio de seus efeitos sobre o motor, melhoria na perda por atrito, melhoria na economia de combustível, na redução das emissões e aumento de durabilidade. Com a introdução da tecnologia mecatrônica, os sistemas convencionais mecânicos seriam substituídos por sistemas controlados eletronicamente. $\mathrm{O}$ projeto básico do sistema de refrigeração automotiva manteve-se essencialmente inalterado durante muito tempo, por exemplo, o acionamento da bomba de água do sistema de arrefecimento do motor é proporcional à rotação do motor. Assim, a taxa de fluxo do líquido refrigerante é determinada pela rotação do motor, o que não é ideal para a maioria dos casos.

Assim, uma bomba de água convencional, acionada mecanicamente, pode causar perdas desnecessárias e parasitárias. Por esta razão uma bomba de água com controle eletrônico permitiria um controle da vazão de água do sistema de arrefecimento, independentemente da rotação do motor, propiciando uma redução posterior das perdas parasitárias. Outra vantagem potencial da bomba elétrica de água é a possibilidade de redução do tamanho do radiador, que é uma questão importante no desenvolvimento de sistemas de arrefecimento do motor. Com 
esta flexibilidade no controle, temos uma melhor escolha nos pontos de operação do motor Diesel. Resultados das pesquisas em sistemas de refrigeração avançados foram publicados ao longo dos anos, com foco principal no controle da temperatura do motor com base em estudos simulados, por exemplo, em [2] e [3].

Nos estudos de [4] foi utilizado o software VECSS (Vehicle Engine Cooling System Simulation) para desenvolver e testar vários projetos de controle. O trabalho consistiu no projeto de vários algoritmos empíricos para o controle da rotação da bomba de água do motor Diesel e o controle da posição da válvula termostática. Por exemplo, a rotação da bomba de água do motor pode ser configurada para operar como uma função de qualquer um dos seguintes parâmetros: rotação do motor, temperatura ambiente, juntamente com a temperatura de entrada do líquido de arrefecimento do motor, taxa de fluxo de combustível, velocidade do ar, temperatura de saida do líquido refrigerante, ou a diferença de temperatura do líquido de arrefecimento entre a entrada e saída do motor e temperatura da parede dos cilindros. Este estudo foi importante também por ter utilizado um software de simulação, VECSS, para mostrar pela primeira vez o potencial de se utilizar um microcontrolador e um algoritmo de controle para controlar o sistema de arrefecimento do motor. Seus algoritmos foram testados e refinados usando VECSS e os resultados foram validados em um motor de referência em dinamômetro. Um microprocessador integrado com as funções de controle e um hardware adequado para atuar no sistema de arrefecimento aplicado ao motor Diesel, e os resultados dos testes foram comparados com aqueles obtidos a partir dos resultados no VECSS e no dinamômetro, propiciando as seguintes conclusões:

$>\quad$ controlar o fluxo do líquido refrigerante mantendo a temperatura de água do motor e a temperatuda óleo lubrificante controladas, para manter a temperatura da parede dos cilindros entre $130^{\circ} \mathrm{C}$ e $180^{\circ} \mathrm{C}$, melhora a eficiência térmica a baixas temperaturas nas condições de partida a frio e a redução nos niveis das emissões de poluentes;

> o controle da rotação da bomba de água elétrica e, por consequência, da vazão independente da rotação do motor, contribui para maior eficiência térmica e economia de combustível;

$>\quad$ considerando-se que as temperaturas das partes metálicas do motor tendem a aumentar mais rapidamente com menores taxas de fluxo do liquido refrigerante e isso aumenta o desgaste e diminui a vida útil do motor, a introdução do controle de temperatura e da bomba de água elétrica promove uma diminuição do desgaste e um aumento na vida útil do motor; e

$>$ a diminuição do tempo de ativação do ventilador em um sistema de refrigeração controlado resulta maior economia de energia e melhora o consumo de combustivel.

Esse estudo, efetuado com o software de simulação VECSS, mostrou as vantagens de um sistema de refrigeração controlada, antes mesmo de ser introduzido em motores Diesel e abriu as portas para muitos outros estudos.

Nos estudos de [5] considera que a bomba de água elétrica tende a revolucionar o sistema de refrigeração dos motores a combustão interna, permitindo o controle do sistema de 
arrefecimento que é na maior parte o responsável pela durabilidade do motor, na emissão de poluentes, no consumo de combustível e no desempenho do motor. Em determinadas situações de operação ocorrerá redução da energia consumida pela bomba elétrica, já que não é necessário o bombeamento do líquido de arrefecimento ou há redução do fluxo de líquido necessário para a resfriamento. A utilização da bomba de água elétrica em motores promove um excelente desempenho para motor, não importa qual combustível é utilizado, pois é fácil de ajustar a temperatura de trabalho do motor para cada tipo de combustível. A liberdade de posicionamento e lay out é outra grande vantagem em usar a bomba de água elétrica, pois não precisa estar acoplada ao bloco do motor, ao contrário do acionamento das bombas mecânicas em que é necessário que haja um acoplamento mecânico por correias e polias ligadas ao eixo do motor diesel. Espera-se uma redução no tamanho do radiador e, assim, a otimização do sistema de arrefecimento. Além dos benefícios já mencionados, o usuário será beneficiado com a redução do tempo de aquecimento do motor. As bombas de água elétrica podem ser usadas como bombas auxiliares ou como bombas principais dos sistemas de refrigeração. Portanto, os novos desenvolvimentos do motor vão surgir com a adoção de bomba d'água elétrica para fazer a troca térmica entre os componentes do motor. Essa aplicação tende a aumentar com as tendências de uso dos sistemas elétricos de maior tensão de alimentação e de ocorrer uma padronização no modelo da bomba água elétrica, dado que é uma bomba de controle padronizado, onde a interface com o motor não é tão crítica. Isso levará a uma redução nos custos, causada pelo aumento no volume de produção.

Outros estudos, tais como [6] mostram que existe um potencial de redução de NOx com controle de temperatura do sistema arrefecimento do motor diesel. A maioria dos trabalhos anteriores no controle da temperatura do sistema de arrefecimento do motor incide sobre os benefícios da economia de combustível e reduzir as emissões de gases de efeito estufa através da redução de perdas por atrito e redução de demanda de energia dos componentes auxiliares.

\section{$\underline{\text { Programas governamentais para controle de emissões }}$}

A emissão de gases é comumente dividida em duas classes: gases de efeito estufa (principalmente $\mathrm{CO} 2$ e $\mathrm{CH} 4)$ e poluentes regulados ( $\mathrm{CO}$, NOx, hidrocarbonetos nãoqueimados, aldeídos e material particulado). Órgãos governamentais em todo o mundo têm atuado como agentes controladores, com o intuito de impor a redução da poluição do ar, obrigando os fabricantes de motores e veículos a buscar soluções tecnológicas capazes de reduzir os níveis de emissões de poluentes. Como um exemplo, a Figura 4 mostra a evolução dos níveis aceitáveis de NOx e de material em partículas, desde 1992, como a norma europeia [7]. Para motores a diesel, os limites da lei para as emissões de NOx são mais restritivas. Sabendo-se que a temperatura influencia diretamente a taxa de formação de NO (óxido nítrico), um método de controle das emissões envolve o controle eficiente da temperatura de combustão. A utilização de um sistema de comando eletrônico dispõe de uma oportunidade de mudar os parâmetros de calibração do motor Diesel para uma melhor relação entre a economia de combustível e emissões NOx (óxido nitroso), CO (monóxido de carbono) e HC (hidrocarboneto). 


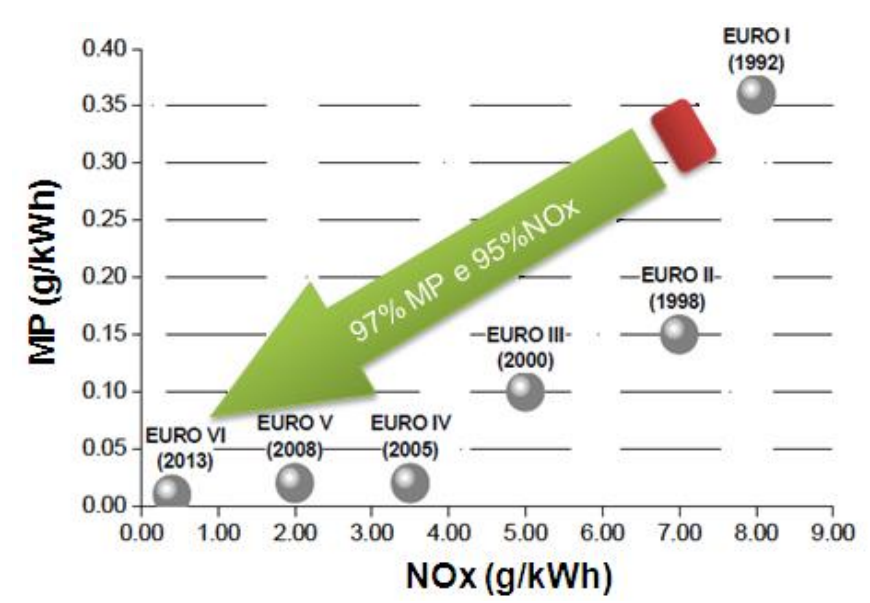

Figura 4 - Gráfico comparativo entre os níveis de emissões de NOx e (MP) Material Particulado da Norma Europeia (EURO).

\section{CONTEXTUALIZAÇÃO}

Este trabalho segue a linha de [4], buscando um projeto de controle mecatrônico de temperatura do sistema de arrefecimento, para manter a temperatura da parede externa do cilindro $T w$ entre $132^{\circ} \mathrm{C}$ e $177^{\circ} \mathrm{C}$ com o objetivo de reduzir emissões e consumo de combustível. Os estudos apontam que isso representa manter a temperatura de saída do liquido de arrefecimento na faixa de $80^{\circ} \mathrm{C}$ a $90^{\circ} \mathrm{C}$, que atende as exigências da aplicação (eficiência, balanço térmico e dos níveis de emissões).

\section{OBJETIVOS}

O objetivo deste trabalho consiste no projeto e a análise de um sistema de controle mecatrônico do sistema de arrefecimento de um motor Diesel, visando um controle da temperatura de água do motor tendo como premissa que isso deverá proporcionar a economia de combustível e a redução das emissões. Para a realização deste objetivo será efetuado a modelagem dos componentes das malhas de controle e será implementado um modelo de cosimulação (Matlab/Simulink e GT-Cool) para fins de análise do sistema completo.

\section{PROJETO PROPOSTO}

O sistema em foco é o sistema de arrefecimento proposto neste trabalho, está sendo mostrada na Figura 5. 


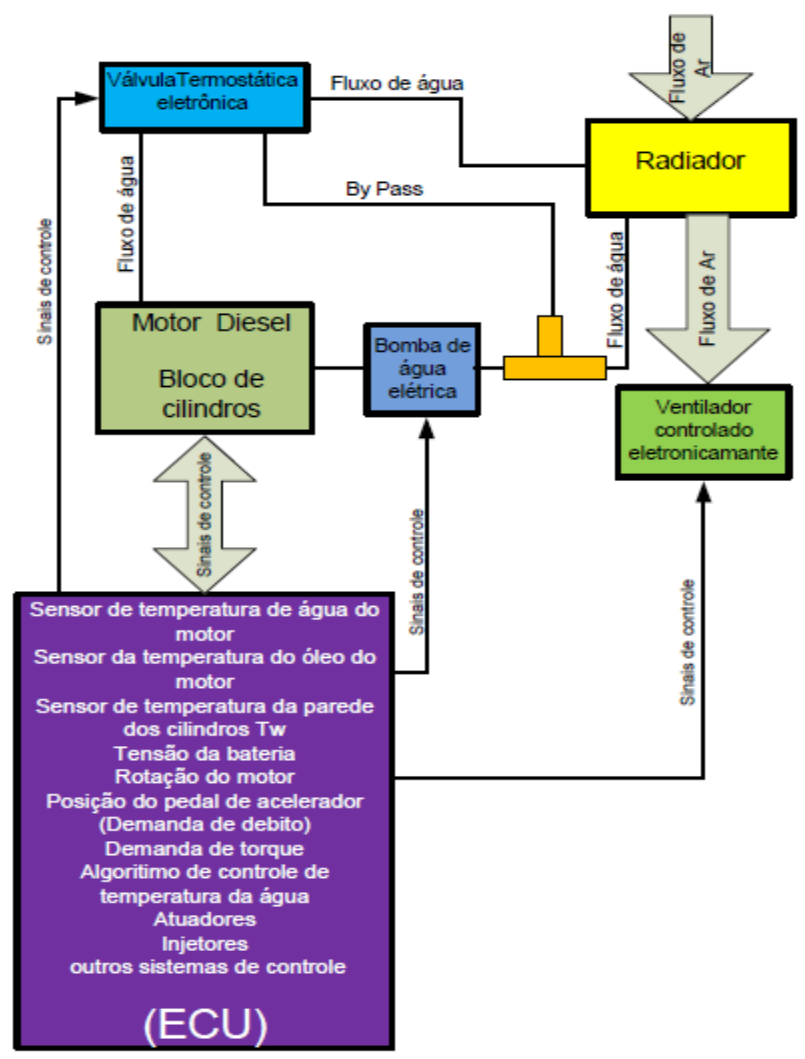

Figura 5 - Sistema de Arrefecimento Proposto

\section{Módulo Eletrônico do Motor (ECU).}

A ECU, módulo eletrônico computadorizado de supervisão e controle do motor, configura o estado da arte em conceitos de controle em malha aberta e fechada que são essenciais para atender a demanda das funções para o correto funcionamento do motor eletrônico de combustão interna, a segurança, a compatibilidade ambiental (emissões), desempenho, e conforto. Esse módulo eletrônico está associado a uma vasta gama de subsistemas automotivos instalados nos veículos modernos. Os sensores do motor são monitorados pelo módulo de controle eletrônico (ECU), e este módulo também converte os sinais necessários para ajustar os elementos finais de controle e atuadores do motor. Como apresentado na Figura 6 os sinais de entrada e saída podem ser: analógicos (por exemplo, características de tensão no sensor de temperatura e de pressão), digital (por exemplo, posição da chave de ignição) ou em forma de pulso (conteúdo de informação, ou seja, como uma função do tempo, por exemplo, sinal de rotação do motor e velocidade do veículo), saída de sinais PWM para controle de diversos dispositivos e atuadores.

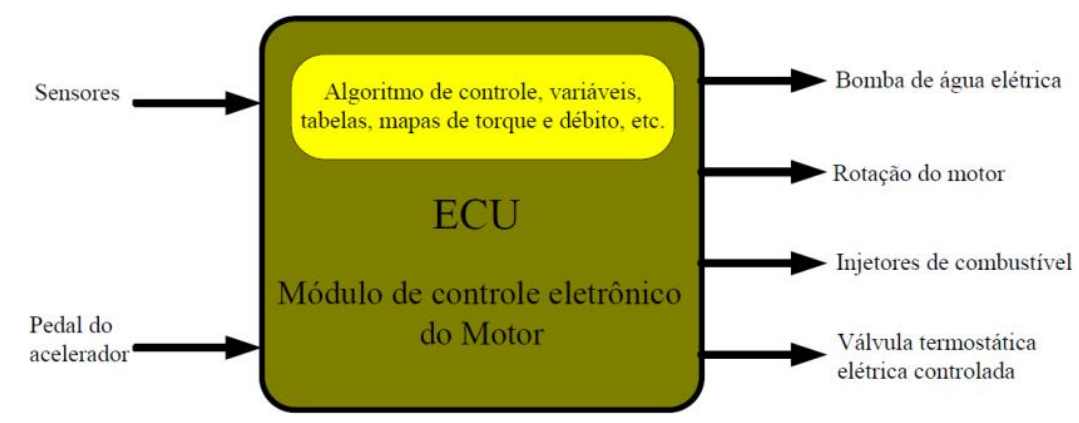

Figura 6 - Ilustração funcional do módulo controle eletrônico do motor (ECM) 


\section{Bomba elétrica de água}

A unidade bomba elétrica de água apresentada na Figura 7 é composta de um motor elétrico e uma bomba de água conectadas ao mesmo eixo e a um dispositivo de controle de rotação. A variação de rotação é determinada pelo controlador de temperatura de água do motor que envia um sinal elétrico do tipo PWM (modulação por largura de pulso) para o dispositivo de controle de rotação da bomba. A variação do percentual PWM está diretamente ligada com a variação de velocidade do motor da bomba elétrica. Desta forma, podemos ter desde o motor parado $0 \%$ de PWM ou até a rotação máxima 100\% de PWM, proporcionando desde pequenas vazões de água até a maxima vazão. A principal característica da bomba elétrica de água é ter o controle de rotação independente da rotação do motor a combustão e forçar o fluxo de água percorrer todo o sistema de arrefeciemento retirando o calor gerado pelo atrito das partes móveis e combustão do motor. A Figura 7 apresenta a bomba elétrica de água com motor brushless (motor elétrico sem escovas). [5].

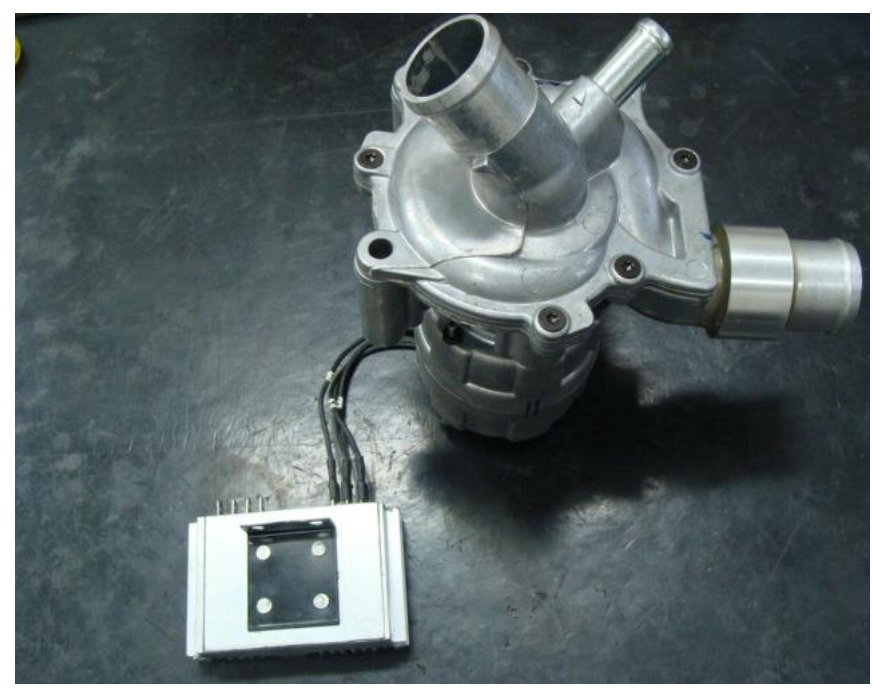

Figura 7 - Bomba elétrica de água com controlador eletrônico de rotação.

\section{$\underline{\text { Válvula termostática controlada eletronicamente }}$}

A temperatura do líquido de arrefecimento e com ela a do motor deve ser regulada para que possam permanecer constantes dentro de uma faixa estreita de trabalho. Uma maneira eficiente para compensar as diferentes condições de trabalho é de se instalar uma válvula termostática controlada eletronicamente, e incorporando um elemento de controle que irá regular a temperatura independente das variações de pressão no sistema de arrefecimento. Uma válvula termostática controlada eletronicamente difere dos termostatos convencionais. $\mathrm{O}$ controlador envia um sinal elétrico do tipo PWM (modulação por largura de pulso) para uma válvula solenoide. A Figura 8 ilustra o funcionamento da válvula solenoide, que faz abrir e fechar o mecanismo interno que controla a membrana ou diafragma da válvula termostática e assim controlando a vazão do liquido de arrefecimento que passa pelo radiador. Este método proporciona ao motor uma ampla gama de trabalho para as diferentes condições climáticas e com grandes flutuações nos fatores de carga do motor e ajuda a reduzir as emissões ao mesmo tempo reduzindo o desgaste do motor. 

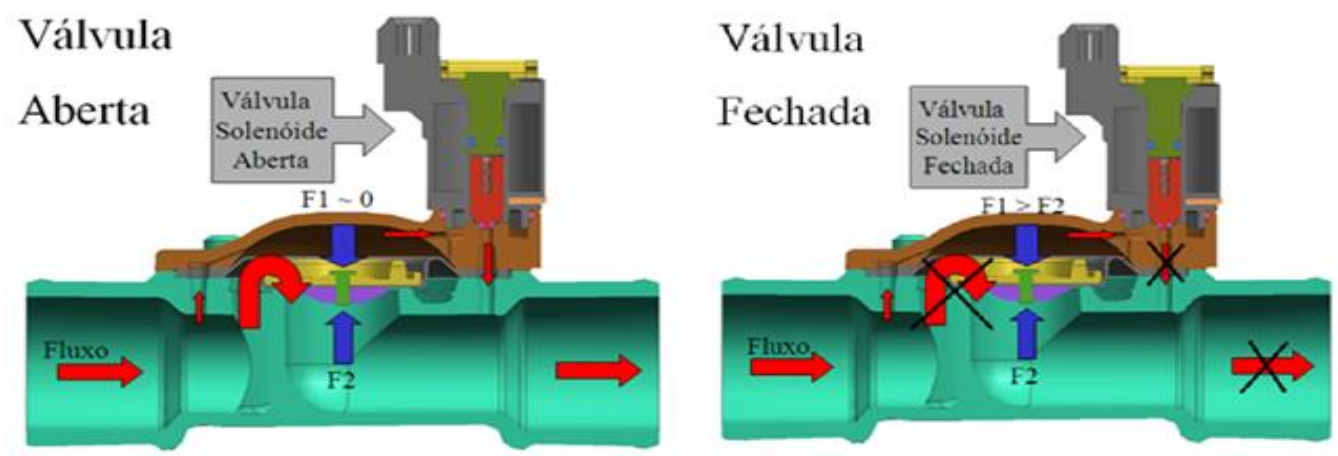

Figura 8 - Válvula termostática eletrônica com mecanismo de controle do fluxo aberto e fluxo fechado. [5]

\section{$\underline{\text { O Ambiente de Simulação }}$}

Para fins de projeto e análise do sistema de controle, construiu-se um modelo de simulação do sistema utilizando-se dois ambientes computacionais: GT-COOL e SIMULINK [8]. O GTSuite é um conjunto integrado de ferramentas de engenharia assistida por computador (CAE) desenvolvido pela Gamma Technologies, Inc. Esse conjunto é composto de seis ferramentas: GT-POWER, GT-COOL, GT-FUEL, GT-DRIVE, GT-VTRAIN e GT-CRANK, e uma interface para construção de modelos (GT-ISE, Interactive Simulation Environment). O Simulink (produto da Mathworks Inc.) é uma ferramenta integrada ao ambiente Matlab, para simulação de sistemas dinâmicos. Neste trabalho, o mecanismo de simulação do sistema de arrefecimento do motor será feito no GT-Power/GT-Cool enquanto que o sistema de controle foi modelado no Simulink.

\section{$\underline{\text { Modelos de Co-Simulação }}$}

Para fins de projeto e análise do sistema de controle, construiu-se um modelo de simulação do sistema utilizando-se dois ambientes computacionais: GT-COOL e SIMULINK [9]. A simulação do sistema de arrefecimento do motor é feita no GT-Power/GT-Cool enquanto que o sistema de controle foi modelado no Simulink. Para um total sincronismo na simulação, os dois modelos devem estar dinamicamente ligados entre si. Isso é possível pelo componente "WiringHarness" do GT-Power, permitindo que sinais sejam enviados e recebidos entre o motor e o sistema de arrefecimento durante a execução da simulação dos modelos. A construção do modelo no software GT-Cool exige alguns dados técnicos do motor de referência, necessários como informações de entrada para o modelo e vários ensaios em dinamômetro foram realizados para esse fim. Entre estes dados, por exemplo, estão a potência de atrito do motor, o consumo especifico, temperaturas etc., para que na simulação do modelo os resultados a serem obtidos representem as condições de operação do motor. O modelo no GT-Cool representa a dinâmica térmica do motor de referência. As entradas deste sistema são a vazão da bomba e a abertura da válvula termostática. A Figura 9 apresenta o diagrama das entradas e saídas para o modelo do sistema de arrefecimento do motor, executado no GTCOOL e controlado via Simulink, ambiente em que é projetado e simulado o controlador. 


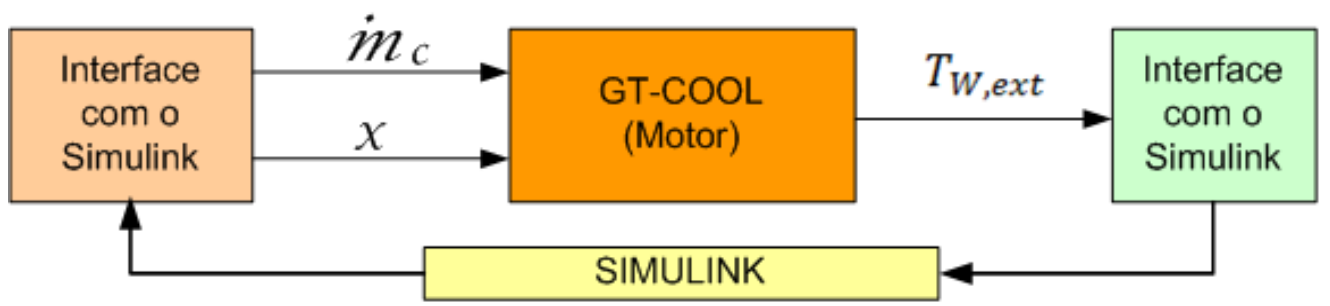

Figura 9 - Diagrama de blocos do modelo GT-COOL/SIMULINK

\section{$\underline{\text { Sistema de controle proposto para o sistema de arrefecimento do motor }}$}

Os modelos e os respectivos parâmetros necessários para se efetuar o projeto dos controladores, foram determinados por meio de ensaios, informações de fabricantes e da bibliografia especializada. A Figura 10 representa o diagrama generalizado de controle do sistema de arrefecimento focalizado neste trabalho.

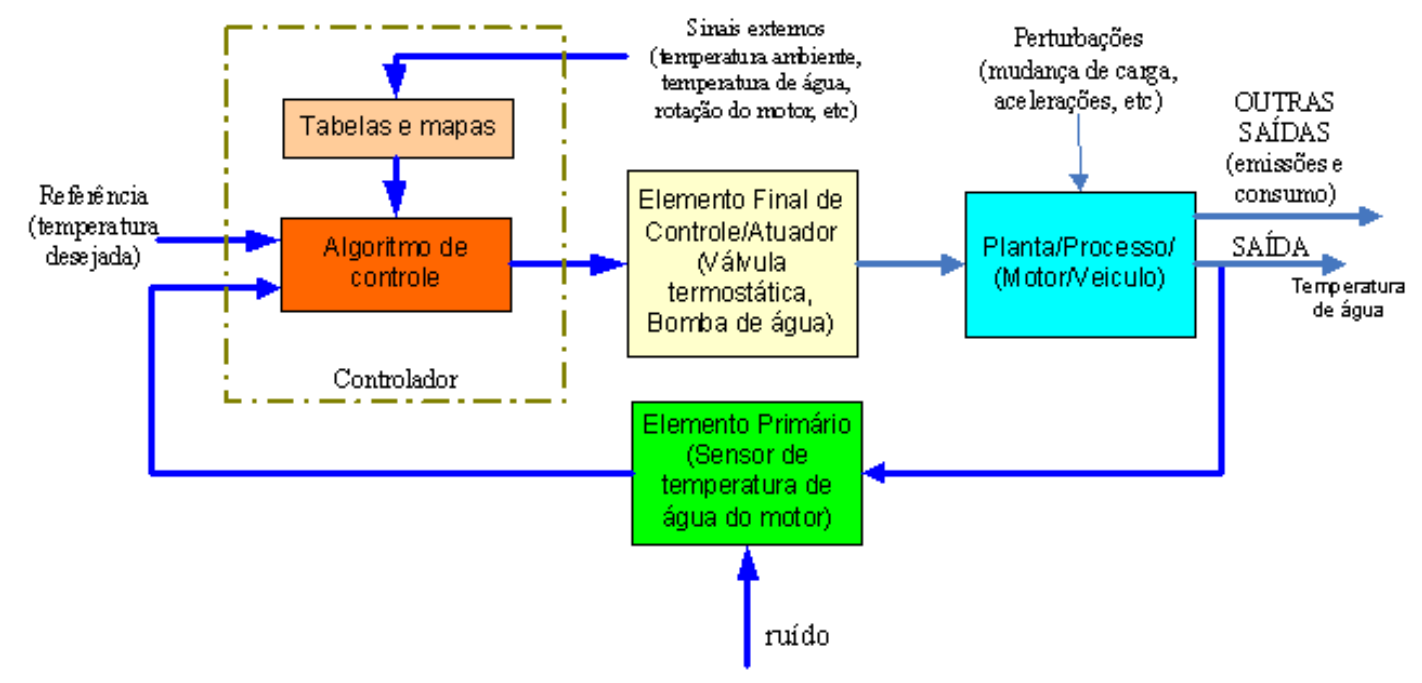

Figura 10 - Diagrama de blocos do sistema de controle

\section{Configurações do sistema de controle}

Na linha do que foi proposto em [4], as variáveis utilizadas são: (TE1) temperatura de entrada do líquido de arrefecimento, (TE3) a temperatura de saída do liquido de arrefecimento, (N) rotação do motor, $(T a m b)$ a temperatura ambiente, $\left(\dot{m}_{f}\right)$ vazão de combustível e $\left(\dot{m}_{c}\right)$ vazão do liquido de arrefecimento. Em conjunto com os parâmetros específicos do sistema, o sistema de controle determina a necessária vazão da bomba elétrica de água e da posição do atuador da válvula termostática (fluxo do líquido de arrefecimento que passa pelo radiador) para manter uma desejada temperatura na parede externa $\left(T_{W_{i} \text { ext }}\right)$ do cilindro como mostra a Figura 11. Três parâmetros de entrada são necessários para calcular a componente de controle "Feed-Forward" e transmitir para o controlador a taxa de vazão para manter uma temperatura desejada na parede exterior do cilindro: vazão de combustível $\left(\dot{m}_{f}\right)$, temperatura de entrada do líquido de arrefecimento (TE1) e temperatura de saída do liquido de arrefecimento do motor (TE3). O sistema de controle da válvula termostática também usa uma componente "Feed-Forward" e uma componente de realimentação para controlar a temperatura desejada de saída do liquido de arrefecimento (TE3). A temperatura de entrada desejada do fluido 
refrigerante é derivada da temperatura desejada da parede externa do cilindro (Twdes), e da temperatura desejada de saída refrigerante (TE3des). Um controlador PID é usado no controle em malha fechada da temperatura de entrada do liquido de arrefecimento do motor (TE1). Neste trabalho, optou-se pela efetuação de um processo algorítmico do projeto dos controladores, uma vez que isso permite trabalhar o projeto considerando modelos mais completos e detalhados do sistema. A Figura 11 ilustra a configuração e os ambientes utilizados no projeto algorítmico dos controladores. O modelo do motor e os atuadores foram simulados no ambiente GT-Cool, mais apropriado para esse tipo de aplicação e análise, e resultados de ensaios do motor real forneceram os parâmetros necessários para a simulação desse componente. Outro aspecto positivo no uso do GT-Cool é que a temperatura da parede externa do cilindro (Tw) e outros elementos (vide moldura na Figura 11) são informações propiciadas pelo modelo GT-Cool do motor, evitando neste estágio de projeto a implementação de um estimador. Outros componentes e as ações de controle dos controladores foram modelados no ambiente Matlab/Simulink, dado que o próprio processo de projeto algorítmico dos controladores é efetuado nesse ambiente.

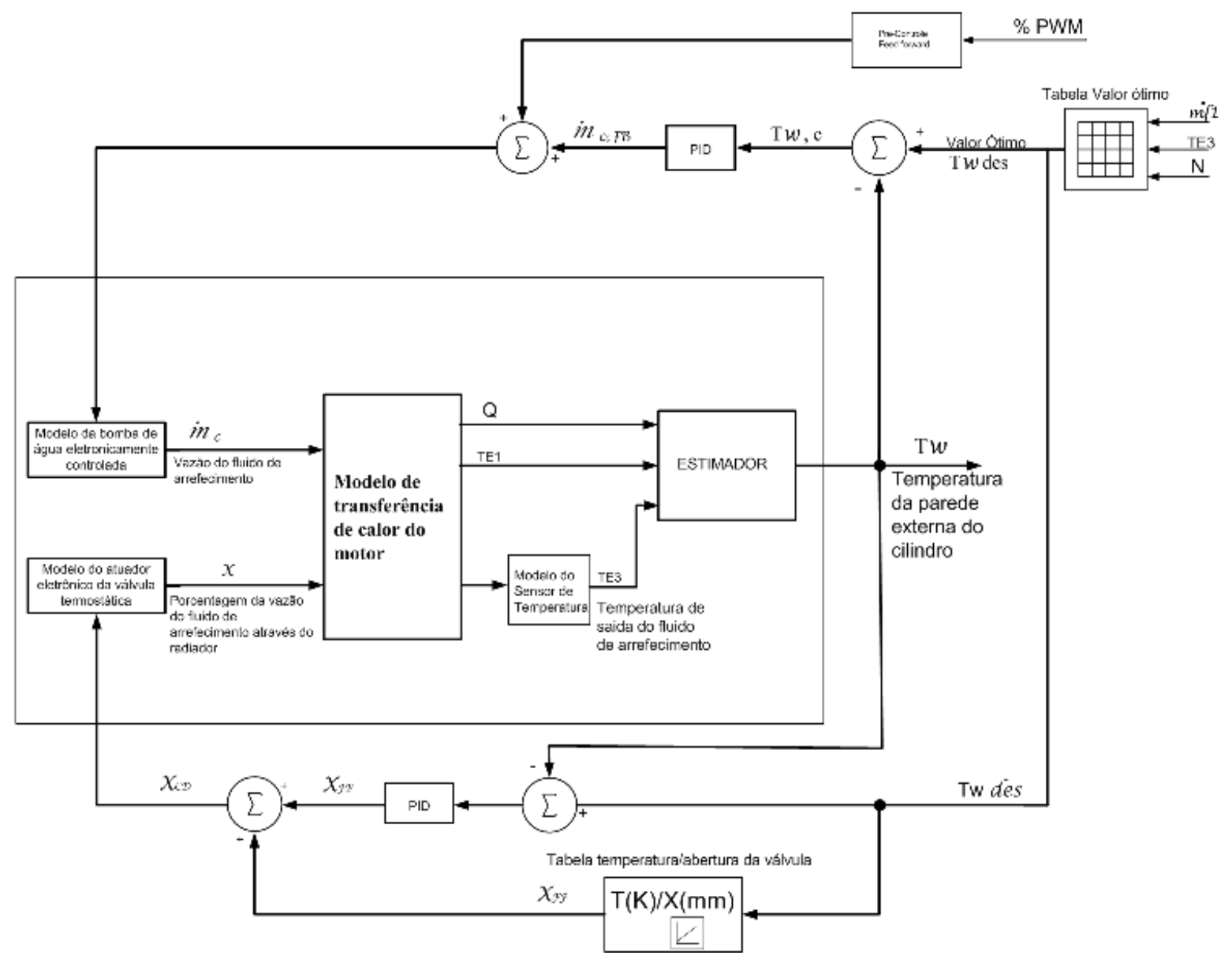

Figura 11 - Diagrama de bloco de controle do sistema de arrefecimento proposto

\section{Construção do modelo no GT-COOL}

Utilizar um modelo computacional como ferramenta de análise tem se tornado muito comum hoje na indústria automotiva, mas para se obter um resultado confiável a ponto de diminuir o número de testes e validações de um produto, é necessário um modelo muito bem construído e calibrado. $\mathrm{O}$ modelo de sistema de arrefecimento foi construído com o auxilio da ferramenta 
de software GT-COOL, da Gamma Technologies[8]. A simulação de componentes desse sistema no GT-COOL é baseada na dinâmica dos fluidos e termodinâmica, o que significa representar o fluxo do fluido e transferência de calor na tubulação, no bloco de cilindros e nos outros componentes do sistema de arrefecimento. Para criar um modelo de simulação no ambiente GT-COOL, utiliza-se uma interface lógica em que cada componente é definido por uma planilha de dados. Os componentes são ligados entre si por linhas de definição do fluxo. Este processo é semelhante à criação de um diagrama de blocos ou modelo no Simulink. O motor Diesel de referência e seu sistema de arrefecimento foram configurados em um modelo nesse ambiente, como apresentado na Figura 12. Vários módulos da biblioteca do GT-COOL foram configurados de forma a simular os componentes do sistema de arrefecimento do motor de referência. As características dos componentes do sistema de arrefecimento e do motor de referência foram levantadas em ensaios realizados em bancada de testes e em dinamômetro e os dados adquiridos nestes ensaios foram usados para configurar cada um dos módulos no modelo de simulação. O Modelo da Figura 12 representa o motor de referência construído no ambiente GT-COOL, esta modelagem contempla o modelo da bomba elétrica de água, da válvula termostática (válvula de orifício), do radiador e das tubulações determinando o sentido de fluxo do liquido de arrefecimento. Contempla também as informações das condições do meio em que o motor está trabalhando como a temperatura, umidade, pressão. Os requisitos para o projeto do sistema de controle proposto podem incluir muitos fatores como o tempo de resposta a variações do processo e rejeição de distúrbios. O projeto de sistemas de controle envolve ainda aspectos como as características dinâmicas do processo, a saturação de atuadores, as características dos distúrbios no processo e atrasos de transporte. A experiência na área permite concluir que a maioria dos processos pode ser controlada razoavelmente bem com um controlador PID, desde que os requisitos de desempenho do controlador não sejam muito altos.

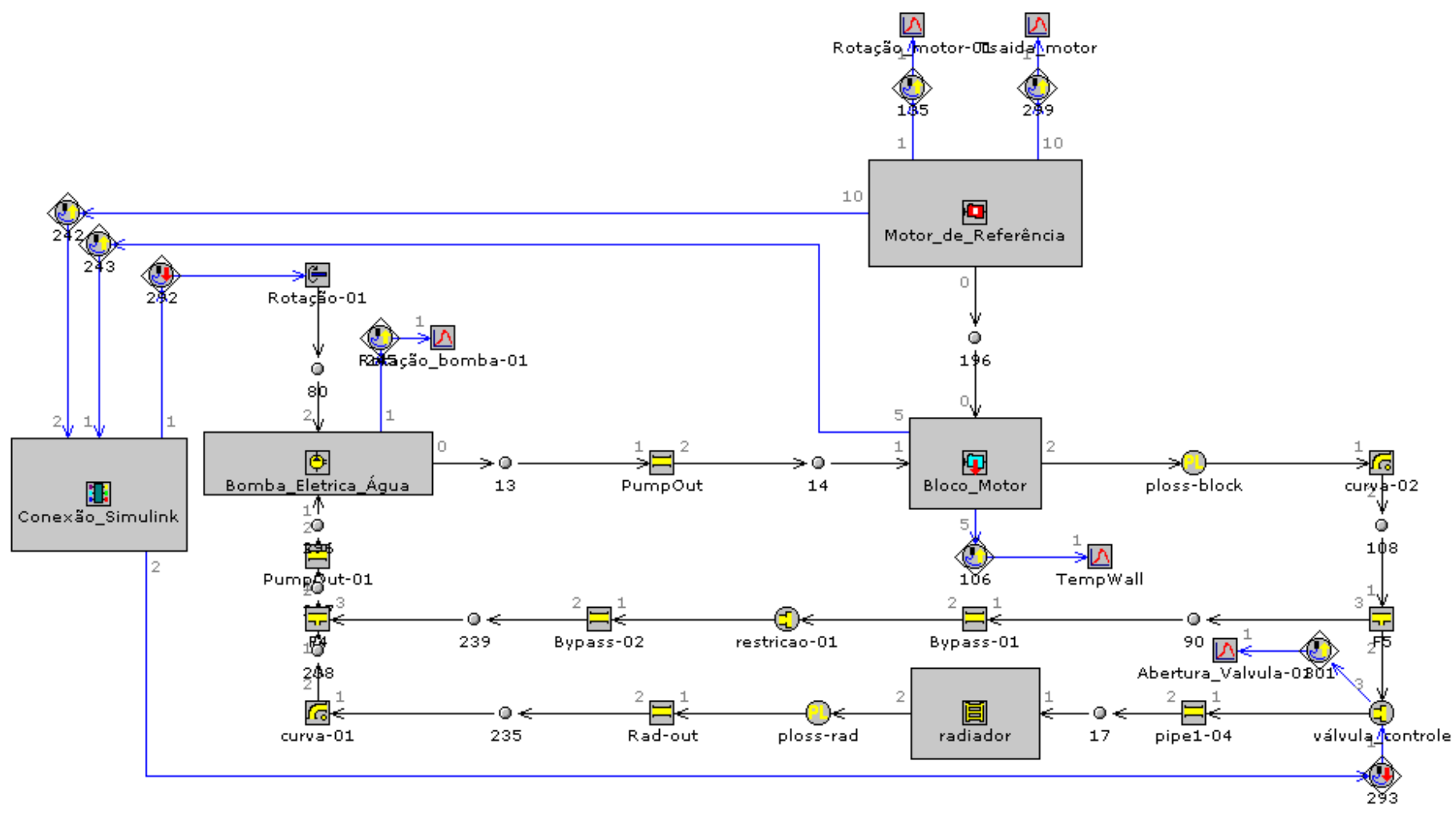

Figura 12 - Modelo no GT-COOL do sistema de arrefecimento utilizado na simulação 


\section{$\underline{\text { Requisitos do projeto de controle }}$}

Os requisitos estabelecidos são:

1) A temperatura de referência é $132^{\circ} \mathrm{C}(405.15 \mathrm{~K})$, temperatura em torno do cilindro e temperatura obtida no ensaio realizado em dinamômetro.

2) A faixa máxima de variação de temperatura é de $+/-5^{\circ} \mathrm{C}(+/-5 \mathrm{~K})$ em torno da temperatura de referência.

3) Para um distúrbio do tipo degrau de $30 \%$ de variação na rotação no motor, o tempo de recuperação (acomodação) para a rejeição do distúrbio deve ser de 15 segundos (tempo de retorno para uma faixa de $+/-3^{\circ} \mathrm{C}(+/-3 \mathrm{~K})$ do valor de referência).

A figura 13 ilustra o diagrama completo de projeto do controlador. A proposta é de controlar a temperatura de água em torno da camisa de cilindros, controlando, assim, a temperatura da câmara de combustão por meio do controle da vazão do liquido de arrefecimento. O sistema é composto por dois atuadores: a bomba elétrica de água e a válvula de controle, modelados no ambiente GT-Cool. O sinal de temperatura da parede de cilindros, Tw, gerado no GT-Cool é enviado para o Simulink, e dois sinais de controle, um para a bomba de água (RPM_B) e outro para a válvula (Pos_V) são enviados para o GT-Cool, através do objeto de interface entre os softwares. O valor da temperatura Tw calculada no GT-Cool passa por um atraso de estimação na resposta do sinal pois o valor da temperatura é um valor calculado. Para manter a temperatura estimada (Tw) próxima ao valor desejado (Tw_des), sempre que houver um erro (diferença) entre ( $\mathrm{Tw}$ _des) e o valor de temperatura estimado, o sistema desencadeará uma ação de controle na bomba de água e na válvula, abrindo-a ou fechando-a, aumentando ou diminuindo a vazão de água do circuito arrefecedor. Os parâmetros de sintonia dos controladores PID consistem nos ganhos $\mathrm{Kp}, \mathrm{Ki}$ e $\mathrm{Kd}$, das respectivas ações em cada um dos controladores. Essa sintonia é feita para o atendimento dos requisitos das malhas de controle, por exemplo, para que seja minimizado um funcional de custo no erro de regulação ou de rastreamento.

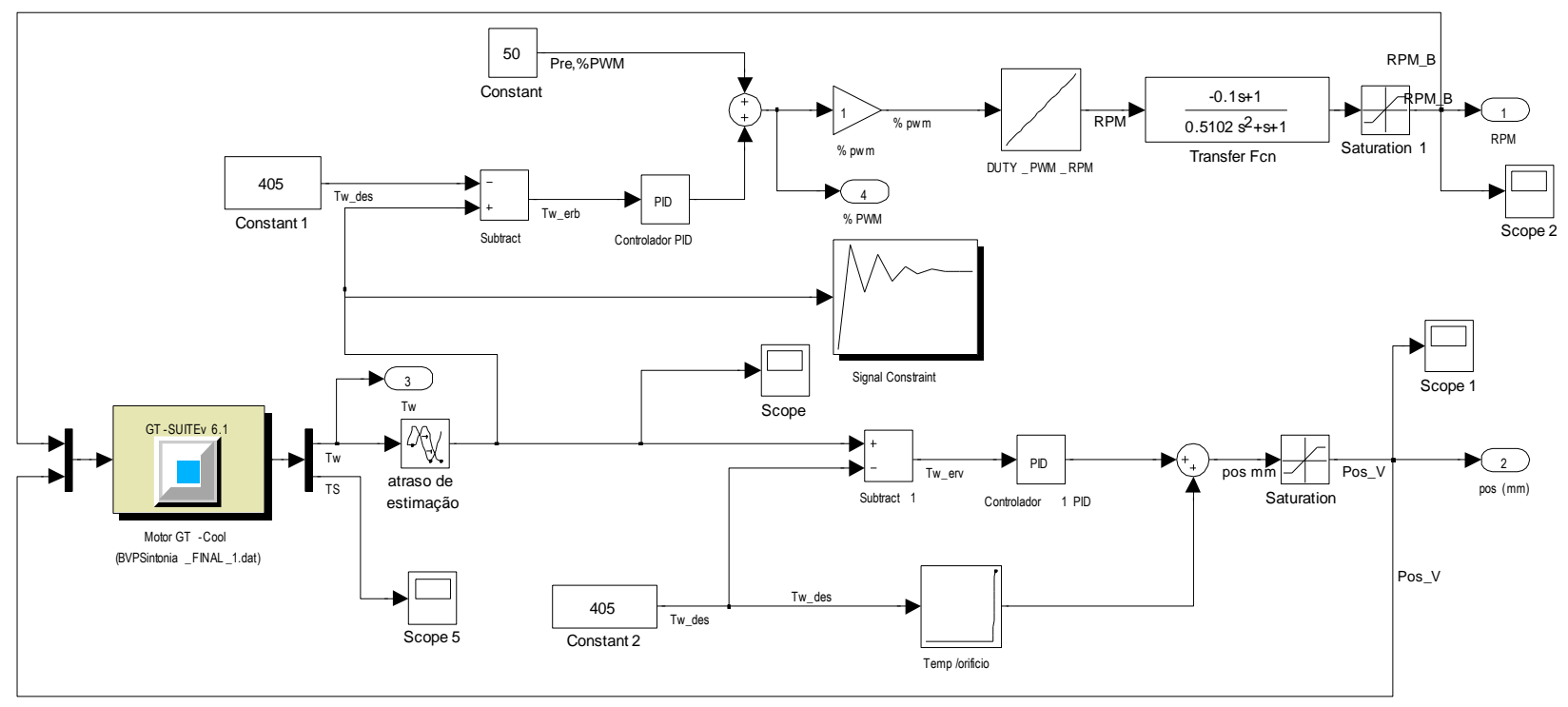

Figura 13 - Diagrama de blocos do sistema para fins de sintonia dos controladores e análise. 


\section{Resultados do projeto de controle da temperatura TW no experimento}

Após o término dos vários testes de simulação com este experimento, uma proposta em reduzir o tempo de acomodação de $15 \mathrm{~s}$ para $10 \mathrm{~s}$ mantendo o distúrbio de $30 \%$ na rotação. A Figura 14 ilustra o tempo de acomodação da temperatura Tw, depois de aplicado o distúrbio tipo degrau de $30 \%$ na rotação do motor.

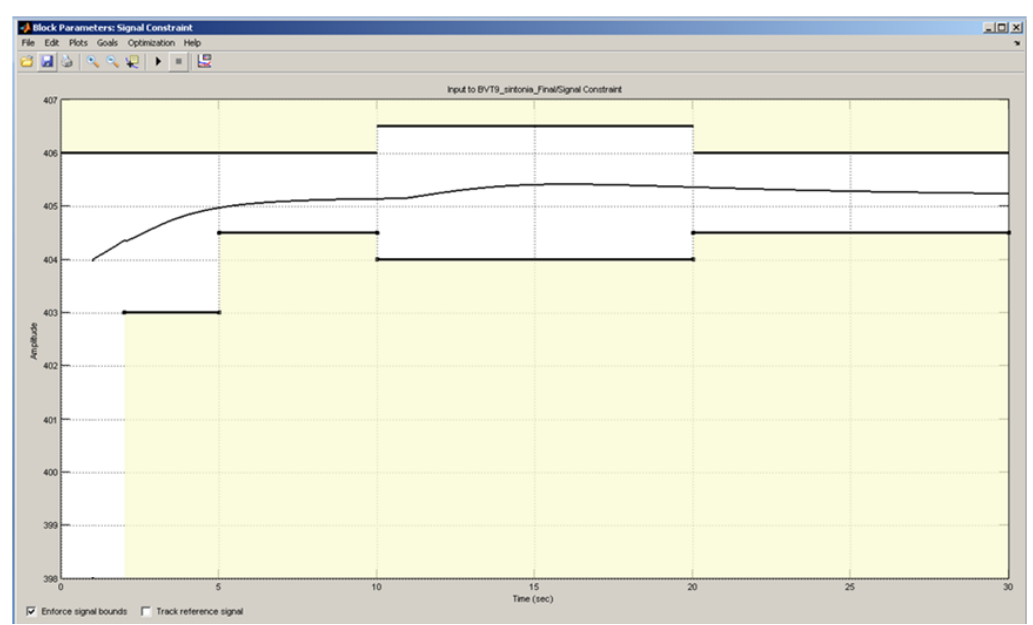

Figura 14 - Gráfico dos resultados de controle de temperatura Tw obtido na simulação

Neste experimento, os ganhos obtidos foram Kp1 $=17.80$, Ki1 $=0.40$ e $\mathrm{Kd} 1=0.890$ para o controlador da bomba e $\mathrm{Kp} 2=1$, Ki2 $=0.10$ e $\mathrm{Kd} 2=0.20$ para o controlador da válvula de orifício. A Figura 15 apresenta o distúrbio na rotação.

Sinal de rotação do motor

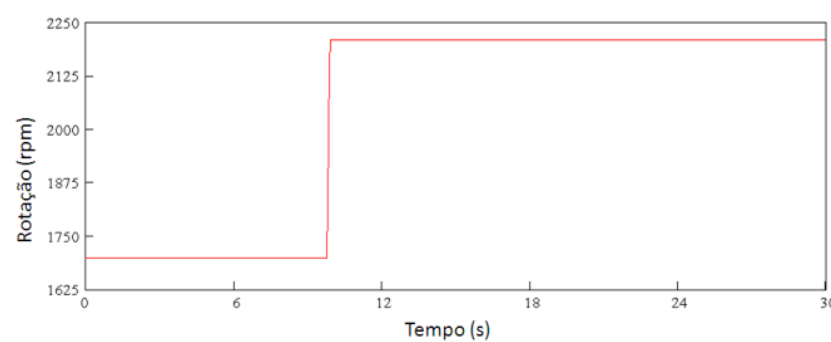

Figura 15 - Distúrbio tipo degrau de $30 \%$ na rotação do motor

Temperatura de água na parede do cilindro Tw (K) - GT-Cool

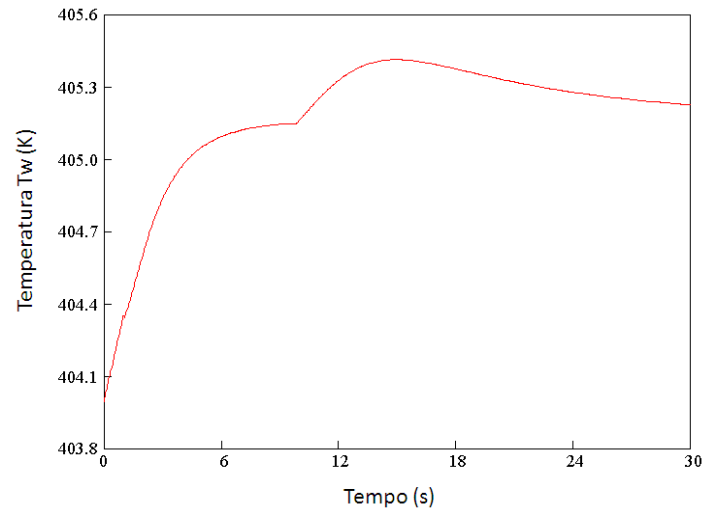

Figura 16 - Tempo de acomodação da temperatura Tw após distúrbio $30 \%$ na rotação do motor 


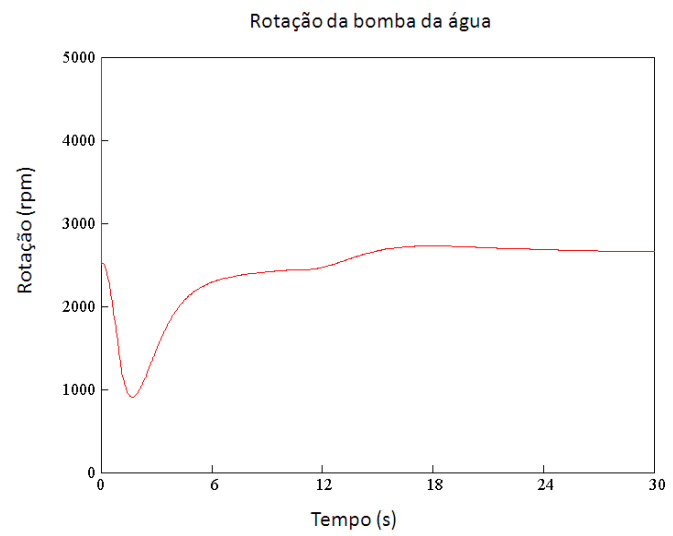

Figura 17 - Sinal de rotação da bomba de água durante o transiente de rotação do motor

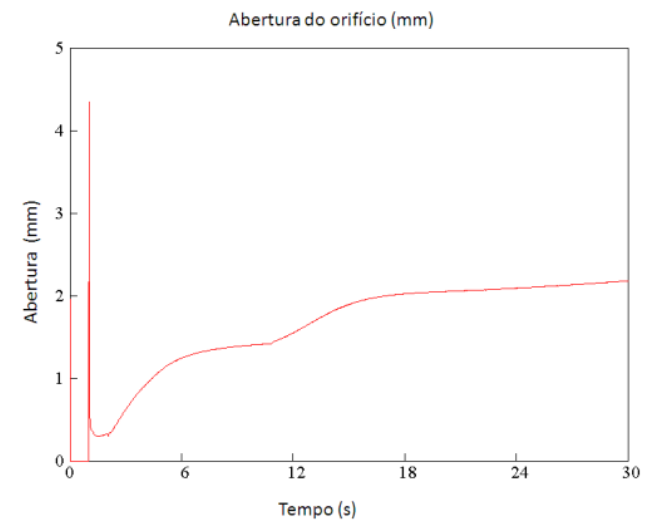

Figura 18 - Sinal de abertura do orifício durante o transiente $30 \%$ de rotação do motor

Como foi observado neste experimento o controle reagiu ao distúrbio atingindo o valor de temperatura Tw.

\section{Ensaio de emissões de gases e consumo de combustível do motor de referência}

O ensaio realizado consiste em manter fixas todas as variáveis do motor e aplicar uma variação na temperatura de água do motor como ilustra a figura 19. Cada incremento no valor da temperatura da água foi de $10^{\circ} \mathrm{C}$, partindo da temperatura água inicial do motor de $50^{\circ} \mathrm{C} \mathrm{e}$ completando o ciclo de teste até a temperatura de $100^{\circ} \mathrm{C}$ de água do motor, durante o ensaio aplicado faz-se a coleta dos dados das variáveis para análise. A análise consiste em medir qual o impacto desta variação nos níveis de emissões dos gases medido pelo analisador e consumo de combustível.

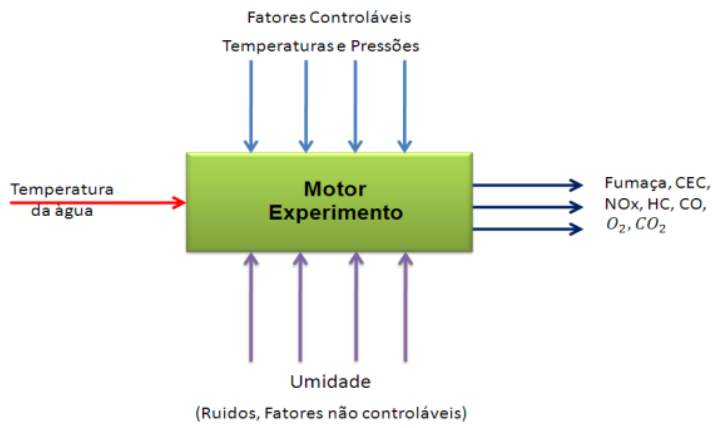

Figura 19 - Esquema do experimento utilizado variando a temperatura de água do motor e observando a saída dos parâmetros de combustão. 


\section{Metodologia utilizada no ensaio de emissões e consumo de combustível}

Como referência será usado nos ensaios o ciclo estacionário de emissões europeu para motores Diesel, ESC (European Stationary Cycle), que foi introduzido no início do ano 2000 com a "Diretiva de emissões 1999/96 CE" apresentado na Figura 20. Neste ensaio selecionamos aleatoriamente a rotação $B$, conforme representados pelos modos $8,4,3$ e 9 , que apresentam diferentes valores de torque.

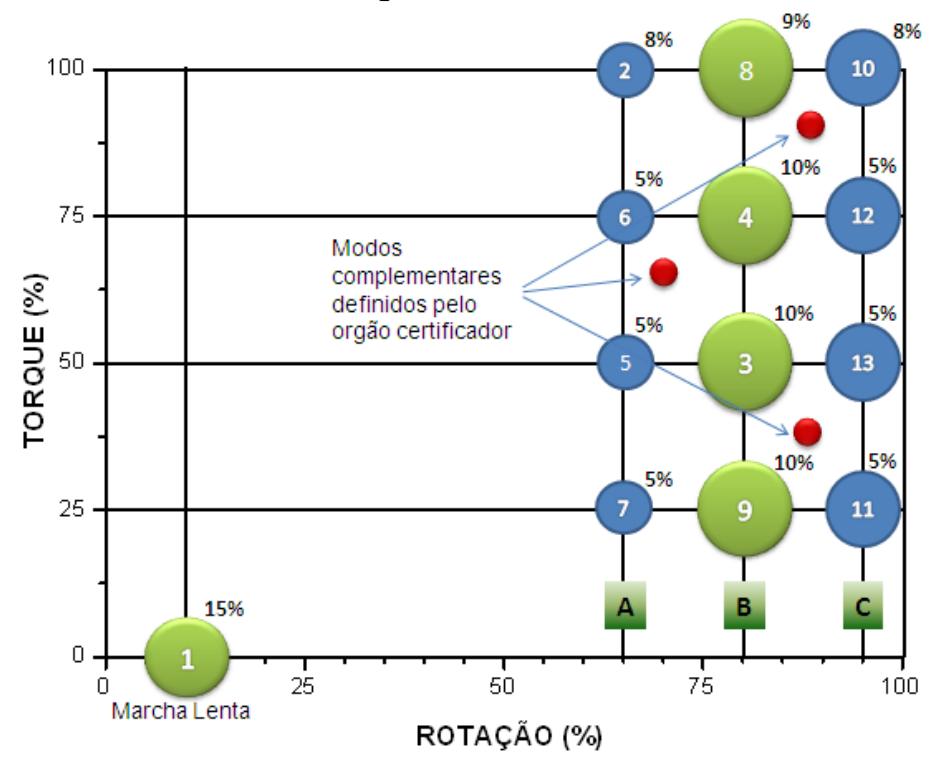

Figura 20 - Ciclo estacionário europeu (ESC) com os 13 modos em função da rotação e torque.

Os valores seguidos neste ensaio no ciclo ESC, os pontos da rotação B, são de $25 \%$ de carga no modo 9 , de $50 \%$ de carga no modo 3 , de $75 \%$ de carga no modo 4 e $100 \%$ de carga no modo 8. Ao final do ensaio a análise das variações de emissões e consumo de combustível em função dos diferentes valores de temperatura da água do motor.

Abaixo segue a sequência do ensaio realizado:

Com a temperatura de água do motor ajustada inicialmente em $50^{\circ} \mathrm{C}$ mantendo-a constante e efetuar a leitura completa das variáveis do motor nos modos $8,4,3$ e 9 . Ajustar para $60^{\circ} \mathrm{C}$ mantendo-a constante e efetuar a leitura completa das variáveis do motor nos modos $8,4,3 \mathrm{e}$ 9. Ajustar a temperatura de água para $70^{\circ} \mathrm{C}$ mantendo-a constante e efetuar a leitura completa das variáveis do motor nos modos $8,4,3$ e 9 . Ajustar para $80^{\circ} \mathrm{C}$ mantendo-a constante e efetuar a leitura completa das variáveis do motor nos modos 8, 4, 3 e 9. Ajustar a temperatura de água do motor ajustada para $90^{\circ} \mathrm{C}$ mantendo-a constante e efetuar a leitura completa das variáveis do motor nos modos 8, 4, 3 e 9. Ajustar a temperatura de água do motor ajustada para $100^{\circ} \mathrm{C}$ mantendo-a constante e efetuar a leitura completa das variáveis do motor nos modos 8, 4, 3 e 9. Além das condições de contorno mencionadas anteriormente, outras variáveis de suma importância para o processo de combustão são os parâmetros de combustão, que foram também rigorosamente controlados para assegurar que as alterações obtidas nos resultados de emissões de gases de escape fossem única e exclusivamente consequência da utilização dos diferentes valores de temperatura de água do motor. 
$\underline{\text { Torque e potência para cada modo ensaiado }}$

Para cada modo em estudo possui diferentes valores de torque e potência e, consequentemente, o que permite observar que não houve variação, mesmo aplicando diferentes níveis de temperatura de água no sistema de arrefecimento. A Figura 21 apresenta os diferentes valores de torque e potência para cada modo ensaiado
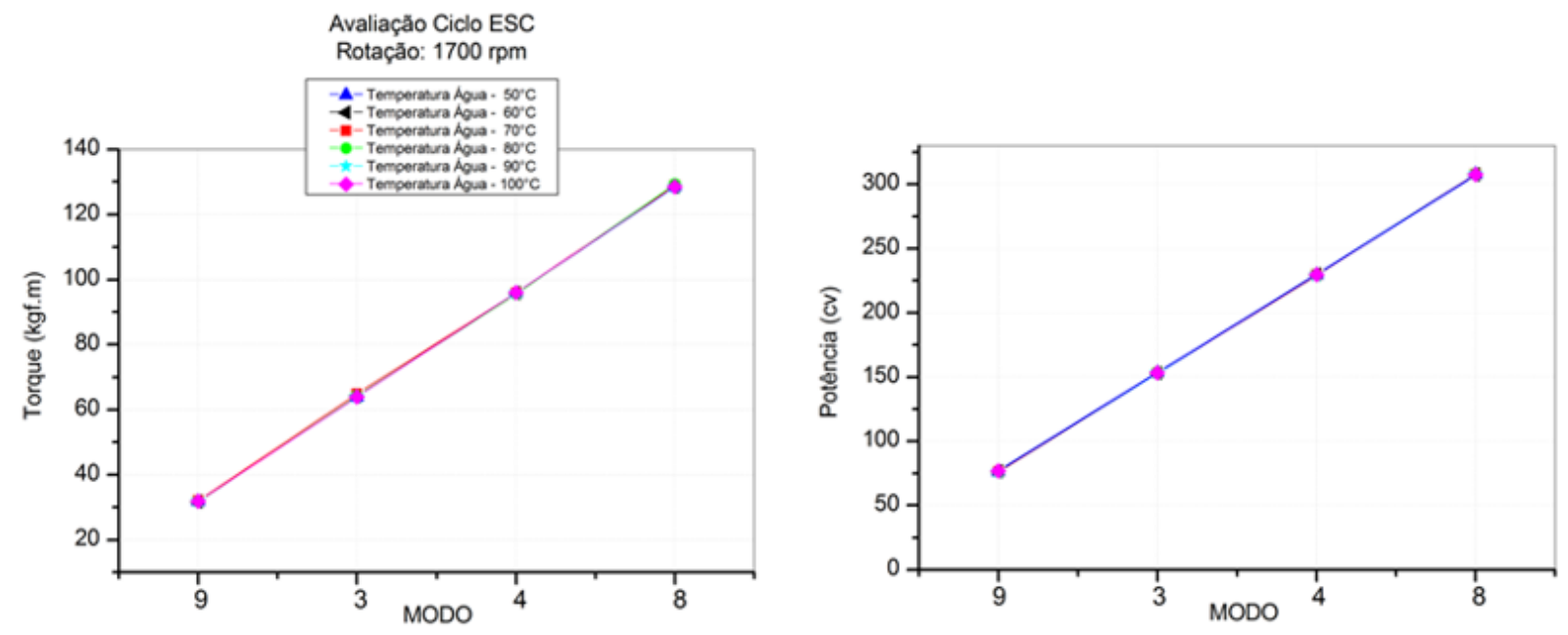

Figura 21 - Gráfico dos valores de torque e potência para cada modo ensaiado.

$\underline{\text { Valores de NOx obtidos durante os ensaios }}$

Como podemos observar, quanto maior a quantidade de combustível queimado, mais calor é gerado e um aumento significativo de temperatura no cilindro. Maiores temperaturas produzem energia suficiente para que ocorram os mecanismos de reações químicas, causando assim maiores formações de NOx como observado nas temperaturas de $80^{\circ} \mathrm{C}, 90^{\circ} \mathrm{C} \mathrm{e} 100^{\circ} \mathrm{C} \mathrm{e}$ comportamento inverso nas temperaturas de $50^{\circ} \mathrm{C}, 60^{\circ} \mathrm{C}$ e $70^{\circ} \mathrm{C}$, ou seja, menores formações de NOx como apresentado na Figura 22.

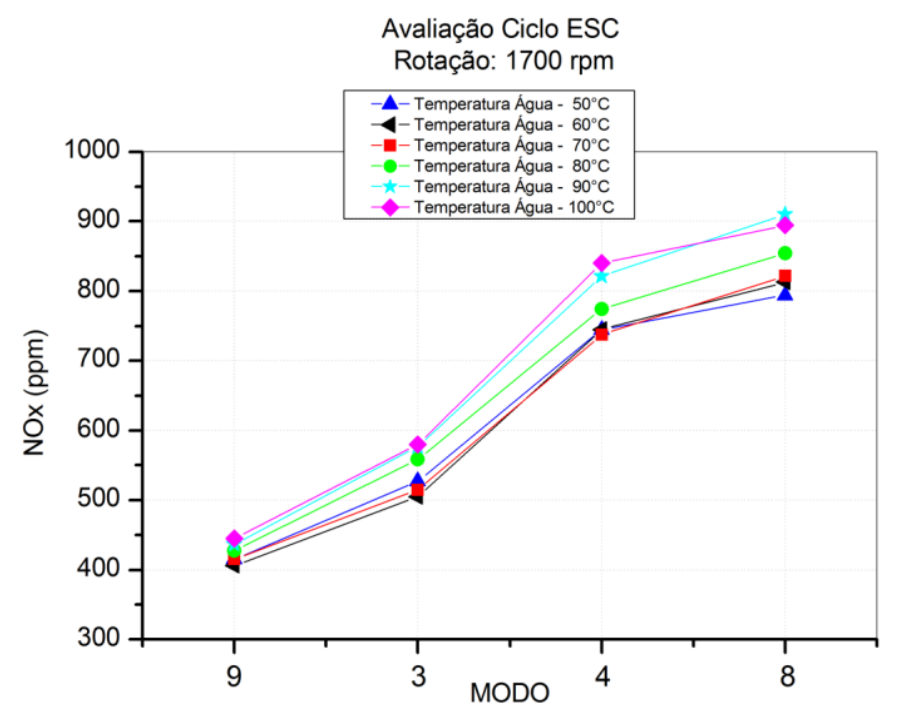

A Figura 22 - Gráfico dos valores de NOx obtidos durante os ensaios para cada modo ensaiado. 
O material particulado (MP) está diretamente ligado à emissão de CO. Como o NOx teve um aumento com as maiores temperaturas obviamente $\mathrm{CO}$ e material particulado (MP) tiveram uma redução. $\mathrm{Na}$ análise das emissões de $\mathrm{HC}$ que nos motores Diesel são compostos basicamente por moléculas de combustível decompostas e óleo lubrificante não podemos dizer que houve uma tendência de aumento ou redução dos hidrocarbonetos em função da temperatura de água. As variações dos valores estão dentro da precisão de leitura do analisador (HORIBA). Na Figura 23 o consumo específico de combustível, também é calculado em função dos valores de potência e vazão mássica de combustível. O ensaio mostrou diferenças entre os resultados nas diferentes temperaturas de água em cada modo ensaiado. Conforme podemos observar na Figura 23 os resultados do consumo entre as temperaturas de água $80^{\circ} \mathrm{C}, 90^{\circ} \mathrm{C}$ e $100^{\circ} \mathrm{C}$ apresentam um comportamento similar, ou seja, melhor rendimento do motor e melhores valores de consumo.

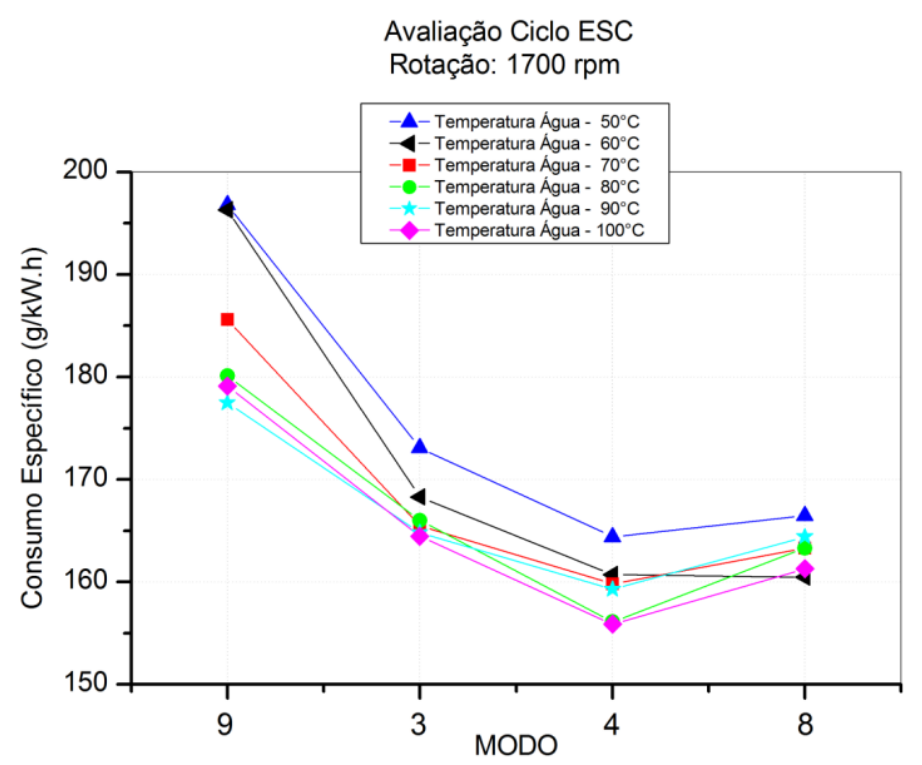

Figura 23 - Gráfico dos valores do consumo específico de combustível

Assim podemos concluir que com alta temperatura de água temos menores consumo de combustível e maior emissão de NOx e com baixa temperatura da água temos maiores consumo de combustível e baixo nível de NOx.

\section{CONCLUSÃO}

Os resultados descritos na literatura técnica especializada, bem como a experiência acumulada na MWM International Motores e ensaios efetuados no contexto deste trabalho, permitem antever a utilização de um sistema de arrefecimento do motor controlado eletronicamente, tende a reduzir, simultaneamente, o consumo de energia, a temperatura da parede do cilindro e as flutuações da temperatura, a fim de reduzir o consumo de combustível e redução nas emissões. A melhoria na economia de combustível vem também na redução da alimentação dos acessórios pelo motor, como a desativação do ventilador. Além disso, resultados experimentais encontrados na literatura e constatados em ensaios reais já efetuados, mostram que o NOx foi reduzido significativamente, controlando-se a temperatura de água do motor, 
também o consumo de combustível mostrou um comportamento favorável à redução com o controle da temperatura da água. Houve também a redução dos gases $\mathrm{CO}_{2}$ e $\mathrm{HC}$.

\section{REFERÊNCIAS}

[1] DIESELNET. Available at: 〈www.dieselnet.com> searched on: May, $10^{\text {th }} 2016$.

[2] Xu, Z., Johnson, J. H., and Chiang, E. C., 1984, "A Simulation Study of a Computer Controlled Cooling System for a Diesel Powered Truck”, SAE paper 841711.

[3] Brian J Luptowski, 2005. "Development of the Enhanced Vehicle and Engine Cooling System Simulation and Application to Active Cooling Control" Technical Paper 2005-010697.

[4] Chad Lehner, et al., 2001., SAE "Design and Development of a Model Based Feedback Controlled Cooling System for Heavy Duty Diesel Truck Applications Using a Vehicle Engine Cooling System Simulation” Technical Paper 2001-01-0336.

[5] Ribeiro, Eduardo, et al. 2007. "Electric Water Pump for Engine Cooling" Technical Paper 2007-01-2785.

[6] H. H. Pang., 2004. "Potential of a Controllable Engine Cooling System to Reduce Nox Emissions in Diesel Engines “, Technical Paper 2004-01-0054.

[7] EURO V "Regulation (EC) No 715/2007 of the European Parliament and of the Council of 20 June 2007".

[8] Gamma Technologies. “GT-COOL Tutorials Version 6.1“, 2006.

[9] Mathworks Inc. "Matlab and Simulink Student Suite". 